\title{
Vital Signs: Prevalence of Key Cardiovascular Disease Risk Factors for Million Hearts 2022 — United States, 2011-2016
}

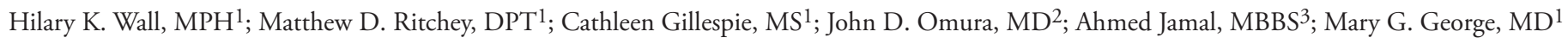

\section{Abstract}

Introduction: Despite decades-long reductions in cardiovascular disease (CVD) mortality, CVD mortality rates have recently plateaued and even increased in some subgroups, and the prevalence of CVD risk factors remains high. Million Hearts 2022, a 5-year initiative, was launched in 2017 to address this burden. This report establishes a baseline for the CVD risk factors targeted for reduction by the initiative during 2017-2021 and highlights recent changes over time.

Methods: Risk factor prevalence among U.S. adults was assessed using data from the National Health and Nutrition Examination Survey, National Survey on Drug Use and Health, and National Health Interview Survey. Multivariate analyses were performed to assess differences in prevalence during 2011-2012 and the most recent cycle of available data, and across subgroups.

Results: During 2013-2014, the prevalences of aspirin use for primary and secondary CVD prevention were 27.4\% and $74.9 \%$, respectively, and of statin use for cholesterol management was 54.5\%. During 2015-2016, the average daily sodium intake was $3,535 \mathrm{mg} /$ day and the prevalences of blood pressure control, combustible tobacco use, and physical inactivity were $48.5 \%, 22.3 \%$, and $29.1 \%$, respectively. Compared with 2011-2012, significant decreases occurred in the prevalences of combustible tobacco use and physical inactivity; however, a decrease also occurred for aspirin use for primary or secondary prevention. Disparities in risk factor prevalences were observed across age groups, genders, and $\mathrm{racial} / \mathrm{ethnic}$ groups.

Conclusions and Implications for Public Health Practice: Millions of Americans have CVD risk factors that place them at increased risk for having a cardiovascular event, despite the existence of proven strategies for preventing or managing CVD risk factors. A concerted effort to implement these strategies will be needed to prevent one million acute cardiovascular events during the 5 -year initiative.

\section{Introduction}

Despite steady declines in CVD mortality rates over approximately the last 40 years, heart disease and stroke remain the first and fifth leading causes of death in the United States, respectively, and their associated mortality rates have recently begun to plateau in the general population and even increase among some subpopulations. (1-3) Furthermore, CVD annually accounts for approximately $\$ 330$ billion in direct and indirect costs in the United States: approximately one in seven health care dollars is spent on CVD (4). To address this burden, in 2012, the U.S. Department of Health and Human Services launched Million Hearts, a national initiative co-led by CDC and the Centers for Medicare \& Medicaid Services, with the goal of preventing one million acute cardiovascular events over 5 years. Because important groundwork and progress were made during the first 5 years $(5,6)$, Million Hearts 2022 was launched in 2017 to accelerate the implementation of effective strategies to improve cardiovascular health.
During 2017-2021, Million Hearts 2022 priorities are keeping adults healthy through community-based strategies that reduce combustible tobacco use, sodium intake, and physical inactivity as well as optimizing health care for those with and at risk for CVD through clinical strategies that improve appropriate aspirin use, blood pressure control, cholesterol management, tobacco cessation, and participation in cardiac rehabilitation.* Million Hearts 2022 also has a special focus on selected priority populations at risk, including blacks/African Americans with hypertension, adults aged 35-64 years for whom heart disease mortality rates are rising, adults who have had a previous heart attack or stroke, and persons with mental health or substance use disorders who use tobacco ( 7 ). This report uses several national surveillance systems to provide baseline data and describe recent changes for key CVD risk factors for which accelerated progress must be made to achieve national goals.

\footnotetext{
*Although participation in cardiac rehabilitation is an evidence-based strategy for preventing secondary CVD-related events, it is not considered a key CVD risk factor. Therefore the participation data are not included in this report.
} 


\section{Methods}

Data for this report were gathered from three national surveillance systems: the National Health and Nutrition Examination Survey (NHANES ${ }^{\dagger}$ ), the National Survey on Drug Use and Health (NSDUH ${ }^{\S}$ ), and the National Health Interview Survey (NHIS ). The details for all three surveys have been published previously $(8-10)$.

NHANES is a complex survey of a multistage probability sample of the civilian, noninstitutionalized U.S. population that combines interviews and physical examinations. Data from NHANES from 2011 to 2014 were used to calculate prevalence estimates for aspirin use for primary CVD prevention** among adults aged 50-59 years, aspirin use for secondary CVD prevention ${ }^{\dagger \dagger}$ among adults aged $\geq 40$ years, combined aspirin use "as appropriate" $\$ \mathbb{S}$ among adults aged $\geq 40$ years,

\footnotetext{
$\dagger$ During 2011-2016, unweighted examination response rates ranged from $58.7 \%$ to $69.5 \%$. https://www.cdc.gov/nchs/nhanes.htm.

$\$$ During 2011-2016, weighted interview response rates ranged from $71.2 \%$ to $74.4 \%$. https://datafiles.samhsa.gov/study/national-survey-drug-use-andhealth-nsduh-2011-nid13563; https://datafiles.samhsa.gov/study/nationalsurvey-drug-use-and-health-nsduh-2012-nid13601; https://datafiles.samhsa. gov/study/national-survey-drug-use-and-health-nsduh-2013-nid13555; https://datafiles.samhsa.gov/study/national-survey-drug-use-and-healthnsduh-2014-nid13618; https://datafiles.samhsa.gov/study/national-surveydrug-use-and-health-nsduh-2015-nid16893; https://datafiles.samhsa.gov/ study/national-survey-drug-use-and-health-nsduh-2016-nid17184.

I During 2011-2016, the final response rate for the sample adult component ranged from $79.7 \%-81.7 \%$. https://www.cdc.gov/nchs/nhis.htm.

** The U.S. Preventive Services Task Force recommends initiating low-dose aspirin use for the primary prevention of CVD in adults aged 50-59 years who have no history of CVD, a $\geq 10 \%$ 10-year atherosclerotic CVD (ASCVD) risk, and are not at increased risk for bleeding (https://www.uspreventiveservicestaskforce. org/Page/Document/RecommendationStatementFinal/aspirin-to-preventcardiovascular-disease-and-cancer). Aspirin use in NHANES was defined by self-report or aspirin identified in the prescription medication data files. Participants who were taking an anticoagulant but not taking aspirin/ antiplatelets were excluded as being at increased risk for bleeding. Participants who reported that they stopped taking aspirin because of side effects were excluded. During 2011-2014, among 2,776 adults aged 50-59 years examined in NHANES with complete data to determine aspirin eligibility, 338 met the criteria for aspirin use for primary prevention.

$\dagger \dagger$ Aspirin use for secondary event prevention is recommended for adults aged $\geq 40$ years with a history of CVD, defined as self-reported angina, coronary heart disease, heart attack, or stroke. Aspirin use in NHANES was defined by self-report or aspirin identified in the prescription medication data files. During 2011-2014, among 11,184 adults aged $\geq 40$ years examined in NHANES with complete data to determine aspirin eligibility, 913 met the criteria for aspirin use for secondary prevention.

$\$ \$$ "Aspirin when appropriate" is defined as primary or secondary prevention use among eligible adults. During 2011-2014, 1,251 adults $\geq 40$ years were included in the aspirin when appropriate analyses.
}

and statin use among eligible adults aged $\geq 21$ years. 99 Mean daily sodium intake $(\mathrm{mg} / \mathrm{day})^{* * *}$ among adults aged $\geq 18$ years and blood pressure control ${ }^{\dagger \dagger}$ estimates among adults aged $\geq 18$ years with hypertension were calculated using 2011-2016 NHANES data.

NSDUH is an annual nationwide survey that collects information through face-to-face household interviews about the use of illicit drugs, alcohol, and tobacco among the noninstitutionalized U.S. population aged $\geq 12$ years. Data from the 2011-2016 NSDUH were combined into 2-year cycles to estimate the prevalence of current combustible tobacco use ${ }^{\$ \$ \$}$ among adults aged $\geq 18$ years.

NHIS is an annual, nationally representative, in-person survey of the noninstitutionalized U.S. civilian population. Data from the 2011-2016 NHIS were combined into 2-year cycles

99 The 2013 ACC/AHA guideline recommends statin treatment for persons 1) with clinical atherosclerotic CVD (ASCVD); 2) with low-density lipoprotein cholesterol (LDL-C) $\geq 190 \mathrm{mg} / \mathrm{dL}$; 3) aged 40-75 years with diabetes, LDL-C 70-189 mg/dL, and without clinical ASCVD; or 4) aged 40-75 years without clinical ASCVD or diabetes with LDL-C 70-189 mg/dL, and estimated 10-year ASCVD risk $\geq 7.5 \%$ (https://www.ahajournals.org/ doi/abs/10.1161/01.cir.0000437738.63853.7a; https://www.ahajournals. org/doi/abs/10.1161/01.cir.0000437741.48606.98). Statin use was identified using the NHANES prescription medication data files. During 2011-2014, among 4,358 non-pregnant adults aged $\geq 21$ years in the morning fasting subsample in NHANES with complete data to determine statin eligibility, 1,823 met the criteria for statin use.

*** Dietary sodium intake is estimated from the NHANES Day 1 dietary recall interviews (https:/www.ars.usda.gov/ba/bhnrc/fsrg). During 2011-2016, 15,698 adults aged $\geq 18$ years had a complete and reliable Day 1 dietary recall and were included in the sodium analyses.

††† Defined among adults with hypertension as systolic BP of $<140 \mathrm{~mm} \mathrm{Hg}$ and diastolic BP of $<90 \mathrm{~mm} \mathrm{Hg}$, based on the average of up to three measurements. ACC/AHA released a new hypertension management guideline in November 2017 that uses 130/80 mm Hg to define blood pressure control (https://professional.heart.org/professional/ScienceNews/ UCM_496965_2017-Hypertension-Clinical-Guidelines.jsp). Here, $140 / 90 \mathrm{~mm} \mathrm{Hg}$ is used to define control because that was the standard, as recommended for the general population by the Seventh Joint National Committee on Prevention, Detection, Evaluation, and Treatment of High Blood Pressure, when these data were collected (Chobanian A V, Bakris G,Black H, et al. The Seventh Report of the Joint National Committee on Prevention, Detection, Evaluation, and Treatment of High Blood Pressure: the JNC 7 report. JAMA 2003;289:2560-2572). Among the participants, approximately $95 \%$ had two or three blood pressure measurements during a single physical examination at the mobile examination center. For the remainder with only one blood pressure measurement, that single measurement was used in place of an average. During 2011-2016, of the 16,457 nonpregnant adults aged $\geq 18$ years examined in NHANES with complete blood pressure and medication data, 5,765 were defined as hypertensive and included in the blood pressure analyses.

$\$ \$ \$$ Combustible tobacco use includes the use of cigarettes, cigars, or pipes. The percentage of adults aged $\geq 18$ years who reported smoking cigarettes on at least 1 day during the preceding 30 days and $\geq 100$ cigarettes in their lifetime, or who reported smoking cigars or a pipe on at least 1 day during the preceding 30 days. During 2011-2016, of the 242,283 persons aged $\geq 18$ years included in the NSDUH population, 241,799 were included in the current combustible tobacco use analyses. 
to estimate the prevalence of physical inactivity 999 among adults aged $\geq 18$ years.

Up to three survey cycles (2011-2012, 2013-2014, and 2015-2016) were examined using sex-, age-, and race/ ethnicity-adjusted regression analyses. Sex-, age-, and race/ ethnicity-adjusted t-tests were used to examine prevalence changes comparing 2011-2012 with the most recent data cycle and differences between sex, age, and racial/ethnic groups within the most recent data cycle. Results were considered significant for $\mathrm{p}$-values $<0.05$.

\section{Results}

Clinical Strategies. During 2013-2014, the prevalences of recommended aspirin use for primary and secondary CVD prevention were $27.4 \%$ and $74.9 \%$, respectively, with a significant decrease from 2011-2012 for primary prevention (43.4\%) but not for secondary prevention (Table 1) (Figure 1). Combined, the prevalence of aspirin use "when appropriate" was $60.8 \%$, which represents a significant decline from $69.2 \%$, during 2011-2012 (Figure 1) and equates to an estimated 9.0 million persons not taking aspirin as recommended. The prevalence of aspirin use for secondary prevention was higher among adults aged $\geq 65$ years $(81.4 \%)$ than among those aged $40-64$ years (63.2\%), and among non-Hispanic whites (whites) (77.9\%) compared with Hispanics (51.5\%). The overall prevalence of recommended aspirin use when appropriate was higher among adults aged $\geq 65$ years than among those aged $40-64$ years.

During 2015-2016, the prevalence of blood pressure (BP) control was $48.5 \%$, with no significant changes occurring during 2011-2012 (Figure 1). This equates to an estimated 40.2 million persons with uncontrolled hypertension (Supplementary Figure, https://stacks.cdc.gov/view/cdc/58116). The prevalence of BP control was higher among adults aged $45-64$ years $(53.8 \%)$ than among those aged $18-44$ years $(40.0 \%)$ and $\geq 65$ years $(45.9 \%)$, and among whites $(50.9 \%)$ than among non-Hispanic blacks (blacks) (44.3\%).

The prevalence of cholesterol management through statin use among eligible adults during 2013-2014 was 54.5\%, with no significant change occurring during 2011-2012 (Figure 1). Prevalence was higher among persons aged $\geq 65$ years $(63.5 \%)$ than among those aged 45-64 years (50.3\%), and among whites $(58.3 \%)$ than among Hispanics (33.7\%). An estimated

\footnotetext{
999 The 2008 Physical Activity Guidelines for Americans (https://www.health.gov/ PAGuidelines/) recommend that all adults should avoid inactivity and that some physical activity is better that none. NHIS questions ask about frequency of participation in light to moderate-intensity and vigorousintensity leisure-time physical activities for at least 10 minutes. Questions are phrased in terms of current behavior and lack a specific reference period. Physical inactivity is defined as reporting no light to moderate or vigorous leisure-time physical activity for at least 10 minutes. During 2011-2016, of the 205,493 adults aged $\geq 18$ years included in the NHIS population, 202,941 were included in the physical inactivity analyses.
}

39.1 million adults are not managing their CVD risk through recommended statin use.

Though the prevalence of BP control was higher among adults aged 35-64 years (a Million Hearts priority population) $(52.9 \%)$ than among those aged $\geq 65$ years $(45.9 \%)$, still approximately half do not have their condition under control. The prevalence of statin use when indicated among persons aged 35-64 years $(48.1 \%)$ was lower than that among those aged $\geq 65$ years $(63.5 \%$ ) (Supplementary Table, https://stacks. cdc.gov/view/cdc/58119).

Community Risk Factors. Despite a significant decline in use of combustible tobacco products, from $25.1 \%$ of adults in 2011-2012, to $22.3 \%$ during 2015-2016, an estimated 54.1 million adult users of combustible tobacco products could benefit from cessation interventions (Figure 2). During 20152016 , the prevalence of combustible tobacco use was higher among men (26.7\%) than among women (18.1\%), decreased with increasing age after age $25-44$ years, and varied by race/ ethnicity. Prevalence was higher among whites $(24.0 \%)$ than among Hispanics (16.0\%) and non-Hispanic Asians (10.3\%); however, persons of "other race/ethnicity," which includes American Indians and Alaska Natives, reported the highest prevalence $(30.8 \%)$ of combustible tobacco use (Table 2).

During 2015-2016, the mean daily sodium intake among adults was $3,535 \mathrm{mg} /$ day, with no significant change occurring from 2011-2012 (Figure 2). Sodium intake was higher among men $(4,095 \mathrm{mg} /$ day $)$ than among women $(3,013 \mathrm{mg} /$ day $)$ and decreased with increasing age, from $3,809 \mathrm{mg} /$ day for persons aged 18-44 years to 3,524 mg/day for those aged 45-64 years, and $2,947 \mathrm{mg} /$ day among adults aged $\geq 65$ years.

During 2015-2016, the prevalence of physical inactivity was $29.1 \%$, a small but statistically significant decrease from 30.9\% during 2011-2012 (Figure 2). This represents an estimated 70.7 million adults who currently partake in no leisure time physical activity. The prevalence of physical inactivity was higher among women (30.7\%) than among men (27.3\%), increased with increasing age, and was higher among blacks (36.9\%) and Hispanics (36.1\%) than among whites (26.4\%).

Among the Million Hearts priority population of adults aged 35-64 years, the prevalence of combustible tobacco product use and average daily sodium intake were higher than those among adults aged $\geq 65$ years, while the prevalence of physical inactivity was lower (Supplementary Table, https://stacks.cdc. gov/view/cdc/58119).

\section{Conclusion and Comment}

To reach the Million Hearts 2022 goal of preventing one million acute cardiovascular events over 5 years, substantial progress is needed in reducing CVD-related risk factors. To achieve needed progress, Million Hearts 2022 has set clinical 
TABLE 1. Current prevalence of Million Hearts 2022 clinical strategies to prevent cardiovascular disease among adults - United States, 2013-2014 and 2015-2016

\begin{tabular}{|c|c|c|c|c|}
\hline Clinical strategy/Demographic group & $\%$ (SE) & $(95 \% \mathrm{Cl})$ & No. (millions)* & t-test p-value ${ }^{\dagger}$ \\
\hline \multicolumn{5}{|c|}{ Aspirin use ${ }^{\S}$ when appropriate for primary or secondary preventionף among adults aged $\geq 40$ years - NHANES, 2013-2014 } \\
\hline Total & $60.8(2.1)$ & $(56.5-64.9)$ & 14.0 & - \\
\hline $\begin{array}{l}\text { Sex } \\
\text { Male } \\
\text { Female }\end{array}$ & $\begin{array}{l}58.0(2.8) \\
65.6(3.3)\end{array}$ & $\begin{array}{l}(52.2-63.5) \\
(58.6-72.0)\end{array}$ & $\begin{array}{l}8.5 \\
5.4\end{array}$ & $\begin{array}{r}\text { reference } \\
0.566\end{array}$ \\
\hline $\begin{array}{l}\text { Age group (yrs) } \\
40-64 \\
65-74 \\
\geq 65 \\
\geq 75\end{array}$ & $\begin{array}{l}43.7(3.3) \\
78.9(4.3) \\
81.4(2.7) \\
84.8(3.1)\end{array}$ & $\begin{array}{l}(37.1-50.4) \\
(68.9-86.3) \\
(75.3-86.2) \\
(77.4-90.1)\end{array}$ & $\begin{array}{l}5.4 \\
4.6 \\
8.8 \\
4.3\end{array}$ & $\begin{array}{r}\text { reference } \\
<0.001 \\
<0.001 \\
<0.001\end{array}$ \\
\hline $\begin{array}{l}\text { Race/Ethnicity } \\
\text { White, non-Hispanic } \\
\text { Black, non-Hispanic } \\
\text { Asian, non-Hispanic } \\
\text { Hispanic } \\
\text { Other }\end{array}$ & $\begin{array}{r}65.9(2.1) \\
51.0(5.3) \\
42.2(8.8) \\
45.4(3.6) \\
56.2(15.7)\end{array}$ & $\begin{array}{l}(61.5-70.1) \\
(40.5-61.5) \\
(26.0-60.2) \\
(38.3-52.6) \\
(26.1-82.3)\end{array}$ & $\begin{array}{r}10.7 \\
1.8 \\
0.4 \\
0.9 \\
0.2\end{array}$ & $\begin{array}{r}\text { reference } \\
0.621 \\
0.016 \\
0.061 \\
0.348\end{array}$ \\
\hline \multicolumn{5}{|c|}{ Aspirin use ${ }^{\S}$ when appropriate for primary prevention $\llbracket$ among adults aged 50-59 years - NHANES, 2013-2014 } \\
\hline Total & $27.4(4.1)$ & $(20.0-36.3)$ & 1.9 & - \\
\hline $\begin{array}{l}\text { Sex } \\
\text { Male } \\
\text { Female }\end{array}$ & $\begin{array}{l}27.6(4.4) \\
26.6(6.0)\end{array}$ & $\begin{array}{l}(19.7-37.1) \\
(16.3-40.2)\end{array}$ & $\begin{array}{l}1.6 \\
0.3\end{array}$ & $\begin{array}{r}\text { reference } \\
0.688\end{array}$ \\
\hline $\begin{array}{l}\text { Race/Ethnicity } \\
\text { White, non-Hispanic } \\
\text { Black, non-Hispanic } \\
\text { Asian, non-Hispanic } \\
\text { Hispanic } \\
\text { Other }\end{array}$ & $\begin{array}{c}27.9(4.1) \\
28.8(6.8) \\
\text { - }^{* *} \\
32.4(9.7) \\
\text { - }^{* *}\end{array}$ & $\begin{array}{c}(20.3-36.9) \\
(17.2-44.0) \\
\text { — }^{* *} \\
(16.4-54.0) \\
\text { — }^{* *}\end{array}$ & $\begin{array}{l}1.1 \\
0.6 \\
\text { - }^{* *} \\
0.2 \\
\text { - }^{* *}\end{array}$ & $\begin{array}{c}\text { reference } \\
0.809 \\
\text { - }^{* *} \\
0.617 \\
\text { - }^{* *}\end{array}$ \\
\hline \multicolumn{5}{|c|}{ Aspirin use $\mathrm{e}^{\S}$ when appropriate for secondary prevention? among adults aged $\geq 40$ years - NHANES, 2013-2014 } \\
\hline Total & $74.9(1.8)$ & $(71.1-78.4)$ & 12.1 & - \\
\hline $\begin{array}{l}\text { Sex } \\
\text { Male } \\
\text { Female }\end{array}$ & $\begin{array}{l}78.0(2.5) \\
71.2(3.6)\end{array}$ & $\begin{array}{l}(72.6-82.5) \\
(63.6-77.8)\end{array}$ & $\begin{array}{l}6.9 \\
5.2\end{array}$ & $\begin{array}{r}\text { reference } \\
0.277\end{array}$ \\
\hline $\begin{array}{l}\text { Age group (yrs) } \\
40-64 \\
65-74 \\
\geq 65 \\
\geq 75\end{array}$ & $\begin{array}{l}63.2(4.5) \\
78.9(4.3) \\
81.4(2.7) \\
84.8(3.1)\end{array}$ & $\begin{array}{l}(53.9-71.5) \\
(69.1-86.2) \\
(75.4-86.1) \\
(77.5-90.0)\end{array}$ & $\begin{array}{l}3.5 \\
4.6 \\
8.8 \\
4.3\end{array}$ & $\begin{array}{r}\text { reference } \\
0.108 \\
0.018 \\
0.004\end{array}$ \\
\hline $\begin{array}{l}\text { Race/Ethnicity } \\
\text { White, non-Hispanic } \\
\text { Black, non-Hispanic } \\
\text { Asian, non-Hispanic } \\
\text { Hispanic } \\
\text { Other }\end{array}$ & $\begin{array}{l}77.9(1.7) \\
80.9(4.6) \\
64.3(8.4) \\
51.5(4.4) \\
57.4(17.4)^{\dagger \dagger}\end{array}$ & $\begin{array}{l}(74.2-81.1) \\
(70.3-88.4) \\
(46.5-78.8) \\
(42.8-60.2) \\
(24.9-84.6)^{\dagger+}\end{array}$ & $\begin{array}{l}9.6 \\
1.2 \\
0.4 \\
0.7 \\
0.2\end{array}$ & $\begin{array}{r}\text { reference } \\
0.266 \\
0.116 \\
<0.001 \\
0.242\end{array}$ \\
\hline \multicolumn{5}{|c|}{ Blood pressure contro| $\$ \S$ among adults aged $\geq 18$ years with hypertension ${ }^{\text {ๆๆ }}-$ NHANES, 2015-2016 } \\
\hline Total & $48.5(2.1)$ & $(44.4-52.6)$ & 37.9 & - \\
\hline $\begin{array}{l}\text { Sex } \\
\text { Male } \\
\text { Female }\end{array}$ & $\begin{array}{l}45.2(2.7) \\
51.6(2.7)\end{array}$ & $\begin{array}{l}(40.0-50.6) \\
(46.4-56.8)\end{array}$ & $\begin{array}{l}16.9 \\
21.1\end{array}$ & $\begin{array}{r}\text { reference } \\
0.036\end{array}$ \\
\hline \multicolumn{5}{|l|}{ Age group (yrs) } \\
\hline $18-24$ & 一** & 一** & 一** & 一** \\
\hline $25-44$ & $41.6(3.1)$ & $(35.6-47.8)$ & 4.4 & 0.012 \\
\hline $18-44$ & $40.0(3.1)$ & $(34.1-46.1)$ & 4.6 & 0.004 \\
\hline $45-64$ & $53.8(2.8)$ & $(48.1-59.3)$ & 18.1 & reference \\
\hline $65-74$ & $51.5(3.6)$ & $(44.5-58.4)$ & 8.7 & 0.307 \\
\hline$\geq 65$ & $45.9(3.1)$ & $(39.8-52.1)$ & 14.0 & 0.009 \\
\hline$\geq 75$ & $38.4(3.3)$ & $(32.1-45.0)$ & 5.2 & $<0.001$ \\
\hline
\end{tabular}

See table footnotes on next page. 
Morbidity and Mortality Weekly Report

TABLE 1. (Continued) Current prevalence of Million Hearts 2022 clinical strategies to prevent cardiovascular disease among adults — United States, 2013-2014 and 2015-2016

\begin{tabular}{|c|c|c|c|c|}
\hline Clinical strategy/Demographic group & $\%(\mathrm{SE})$ & $(95 \% \mathrm{Cl})$ & No. (millions)* & t-test p-value ${ }^{\dagger}$ \\
\hline \multicolumn{5}{|l|}{ Race/Ethnicity } \\
\hline White, non-Hispanic & $50.9(2.8)$ & $(45.4-56.4)$ & 26.7 & reference \\
\hline Black, non-Hispanic & $44.3(1.6)$ & $(41.2-47.5)$ & 5.1 & $<0.001$ \\
\hline Asian, non-Hispanic & $38.2(4.1)$ & (30.4-46.6) & 1.3 & 0.012 \\
\hline Hispanic & $44.2(3.0)$ & $(38.3-50.3)$ & 3.9 & 0.126 \\
\hline Other & $46.5(6.7)$ & $(33.8-59.6)$ & 1.0 & 0.493 \\
\hline \multicolumn{5}{|c|}{ Cholesterol management: statin use $\mathrm{e}^{* * *}$ among eligible adults ${ }^{\dagger+\dagger}$ aged $\geq 21$ years - NHANES, 2013-2014 } \\
\hline Total & $54.5(1.8)$ & $(50.9-58.1)$ & 46.9 & - \\
\hline \multicolumn{5}{|l|}{ Sex } \\
\hline Male & $51.5(2.1)$ & $(47.3-55.7)$ & 23.8 & reference \\
\hline Female & $58.1(2.5)$ & $(53.0-63.0)$ & 23.1 & 0.089 \\
\hline \multicolumn{5}{|l|}{ Age group (yrs) $)^{\S \S}$} \\
\hline $21-24$ & -** & - ${ }^{* *}$ & -** & 一** \\
\hline $25-44$ & $37.7(5.7)$ & $(27.0-49.8)$ & 2.6 & 0.083 \\
\hline $21-44$ & $35.7(5.4)$ & $(25.6-47.2)$ & 2.7 & 0.028 \\
\hline $45-64$ & $50.3(2.5)$ & $(45.4-55.3)$ & 21.8 & reference \\
\hline $65-74$ & $52.7(3.0)$ & $(46.5-58.8)$ & 11.8 & 0.787 \\
\hline$\geq 65$ & $63.5(2.2)$ & $(59.0-67.8)$ & 22.3 & $<0.001$ \\
\hline$\geq 75$ & $86.2(3.2)$ & (78.2-91.6) & 10.7 & $<0.001$ \\
\hline \multicolumn{5}{|l|}{ Race/Ethnicity } \\
\hline White, non-Hispanic & $58.3(2.1)$ & $(54.0-62.6)$ & 35.8 & reference \\
\hline Black, non-Hispanic & $44.3(4.0)$ & $(36.3-52.5)$ & 4.6 & 0.013 \\
\hline Asian, non-Hispanic & $49.2(4.0)$ & $(41.2-57.2)$ & 2.0 & 0.092 \\
\hline Hispanic & $33.7(3.2)$ & $(27.6-40.4)$ & 2.8 & $<0.001$ \\
\hline Other & - ** & - ${ }^{* *}$ & 一** & —** \\
\hline
\end{tabular}

Source: NHANES, National Center for Health Statistics, CDC.

Abbreviations: $\mathrm{Cl}=$ confidence interval; NHANES = National Health and Nutrition Examination Survey; $\mathrm{SE}=$ standard error.

* Population counts are calculated using the American Community Survey 2013 or 2015 annual Public Use Microdata Sample files, the latest available file after data collection in the 2013-2014 and 2015-2016 survey cycles, respectively. https://wwwn.cdc.gov/nchs/nhanes/ResponseRates.aspx.

† P-values adjusted for sex, age group, and race/ethnicity using logistic regression.

$\S$ Aspirin use was defined by any of the following: an answer of "yes" to the question "Doctors and other health care providers sometimes recommend that you take a low-dose aspirin each day to prevent heart attacks, strokes, or cancer. Have you ever been told to do this?" and an answer of "yes" or "sometimes" to the question "Are you/ now following this advice?"; an answer of "yes" to the question "On your own, are you now taking a low-dose aspirin each day to prevent heart attacks, strokes, or cancer?" Aspirin identified in the Rx medication data files. Participants who reported taking an anticoagulant (as identified in the prescription medication files) but not taking aspirin were excluded.

I Primary prevention: includes examined adults aged 50-59 years for whom aspirin is recommended by the U.S. Preventive Services Task Force, without a history of cardiovascular (CVD) and with a 10-year atherosclerotic CVD (ASCVD) risk $\geq 10 \%$. (Bibbins-Domingo K. Aspirin Use for the Primary Prevention of Cardiovascular Disease and Colorectal Cancer: U.S. Preventive Services Task Force Recommendation Statement. Ann Intern Med 2016;164:836-45; U.S. Preventive Services Task Force (USPSTF) Recommendation Summary: https://www.uspreventiveservicestaskforce.org/Page/Document/UpdateSummaryFinal/aspirin-to-preventcardiovascular-disease-and-cancer: ASCVD risk score is calculated based on the equations published in Goff DC Jr, Lloyd-Jones DM, et al. 2013 ACC/AHA guideline on the assessment of cardiovascular risk: a report of the American College of Cardiology/American Heart Association Task Force on Practice Guidelines. Circulation. 2014;129:S49-73.) Secondary prevention: includes examined adults aged $\geq 40$ years with a history of cardiovascular disease. A history of CVD is defined as an answer of "yes" to any of the following questions: "Has a doctor or other health professional ever told you that you had angina, also called angina pectoris?", "Has a doctor or other health professional ever told you that you had coronary heart disease?", "Has a doctor or other health professional ever told you that you had a heart attack (also called myocardial infarction)?", "Has a doctor or other health professional ever told you that you had a stroke?"

** Statistically unreliable estimates (relative standard error $>40 \%$ ) are suppressed.

${ }^{+\dagger}$ Estimates are statistically unstable by National Center for Health Statistics standards (relative standard error $>30 \%$ ).

$\S \S$ Blood pressure (BP) control defined as an average systolic BP $<140 \mathrm{~mm} \mathrm{Hg}$ and an average diastolic BP $<90 \mathrm{~mm} \mathrm{Hg}$. Calculated among adults with hypertension. Includes non-pregnant examined adults aged $\geq 18$ years with $\geq 1$ complete blood pressure measurement and information to determine BP-lowering medication use

ใ१ी Hypertension is defined as an average systolic BP $\geq 140 \mathrm{~mm} \mathrm{Hg}$, or an average diastolic BP $\geq 90 \mathrm{~mm} \mathrm{Hg}$, or self-reported current use of BP-lowering medication. Current use of BP-lowering medication is defined as an answer of "yes" to the questions: "Because of your high blood pressure/hypertension, have you ever been told to take prescribed medicine?" and "Are you currently taking medication to lower your blood pressure?"

*** Statin use is defined using the prescription medication files.

$\mathrm{t+ \dagger}^{+}$Includes non-pregnant fasting adults ( $\geq 21$ years) for whom a statin is recommended, based on their risk for ASCVD, as defined in: Stone NJ, Robinson J, Lichtenstein AH, et al. 2013 ACC/AHA guideline on the treatment of blood cholesterol to reduce atherosclerotic cardiovascular risk in adults: a report of the American College of Cardiology/American Heart Association Task Force on Practice Guidelines. Circulation 2014;129:S1-45. 
FIGURE 1. Prevalence of Million Hearts 2022 clinical strategies*,t, to prevent cardiovascular disease among adults ${ }^{\natural, * *}$ - United States, 2011-2012, 2013-2014, and 2015-2016

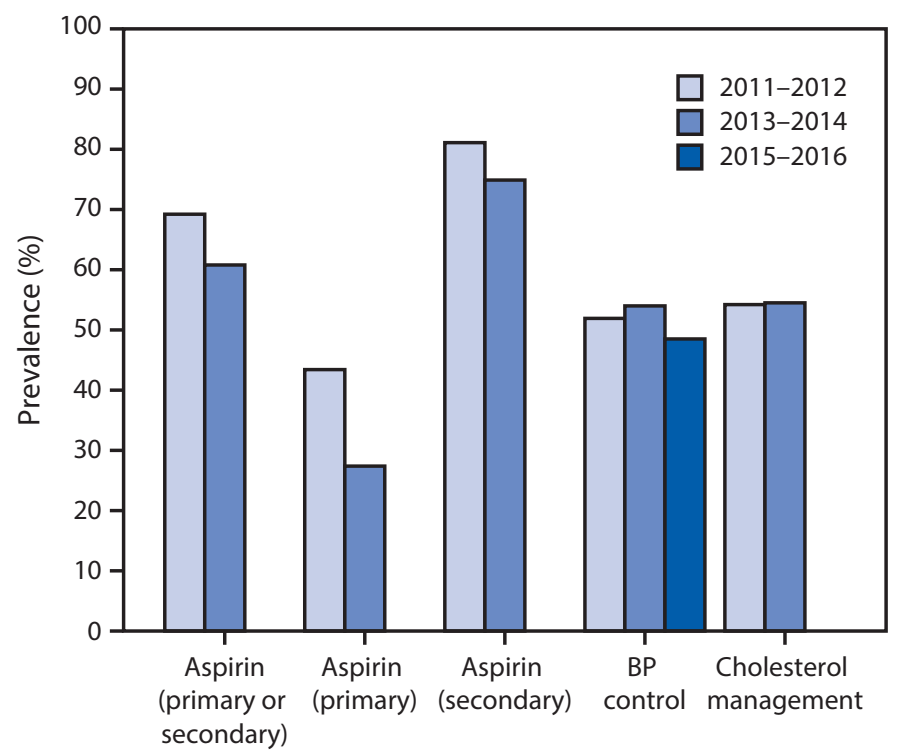

Clinical strategy

Source: National Health and Nutrition Examination Survey, National Center for Health Statistics, CDC.

Abbreviation: $\mathrm{BP}=$ blood pressure.

* Aspirin use was defined by an answer of "yes" to the question "Doctors and other health care providers sometimes recommend that you take a low-dose aspirin each day to prevent heart attacks, strokes, or cancer. Have you ever been told to do this?" and an answer of "yes" or "sometimes" to the question "Are you/ now following this advice?"; an answer of "yes" to the question "On your own, are you now taking a low-dose aspirin each day to prevent heart attacks, strokes, or cancer?"; or aspirin identified in the prescription medication data files. Participants who reported taking an anticoagulant in the prescription medication files but not taking aspirin were excluded. Aspirin use for primary prevention includes examined adults aged 50-59 years without a history of cardiovascular disease (CVD) and with an American College of Cardiology/American Heart Association 10-year atherosclerotic CVD risk score $\geq 10 \%$. Aspirin use of secondary prevention includes examined adults aged $\geq 40$ years with a history of CVD.

${ }^{\dagger} \mathrm{BP}$ control was defined as an average systolic BP $<140 \mathrm{~mm} \mathrm{Hg}$ and an average diastolic BP $<90 \mathrm{~mm} \mathrm{Hg}$ among adults aged $\geq 18$ years with hypertension. Hypertension is defined as an average systolic BP $\geq 140 \mathrm{~mm} \mathrm{Hg}$, or an average diastolic BP $\geq 90 \mathrm{~mm} \mathrm{Hg}$, or self-reported current use of BP-lowering medication.

$\S$ Cholesterol management is defined as current statin use, based on the prescription medication data files, among fasting adults aged $\geq 21$ years for whom statin therapy is recommended.

" For aspirin (primary or secondary), t-test p-value $<0.01$ comparing 2013-2014 with 2011-2012, adjusted for sex, age group, and race/ethnicity.

** For aspirin (primary), t-test $\mathrm{p}$-value $<0.05$ comparing 2013-2014 with 2011-2012, adjusted for sex and race/ethnicity.

targets of $80 \%$ performance on the "ABCS" of CVD prevention: aspirin when appropriate, blood pressure control, cholesterol management, and smoking cessation. At the community level, a 20\% reduction in the prevalence of combustible tobacco product use and of physical inactivity and a $20 \%$ reduction in mean daily sodium intake are targeted. These indicators, along with cardiac rehabilitation participation, are the focus of Million Hearts 2022; progress in reaching indicator targets
FIGURE 2. Prevalence of Million Hearts 2022 community risk factors ${ }^{*, t}, \S$ for cardiovascular disease among adults ${ }^{\text {? }}$ — United States, 2011-2012, 2013-2014, and 2015-2016

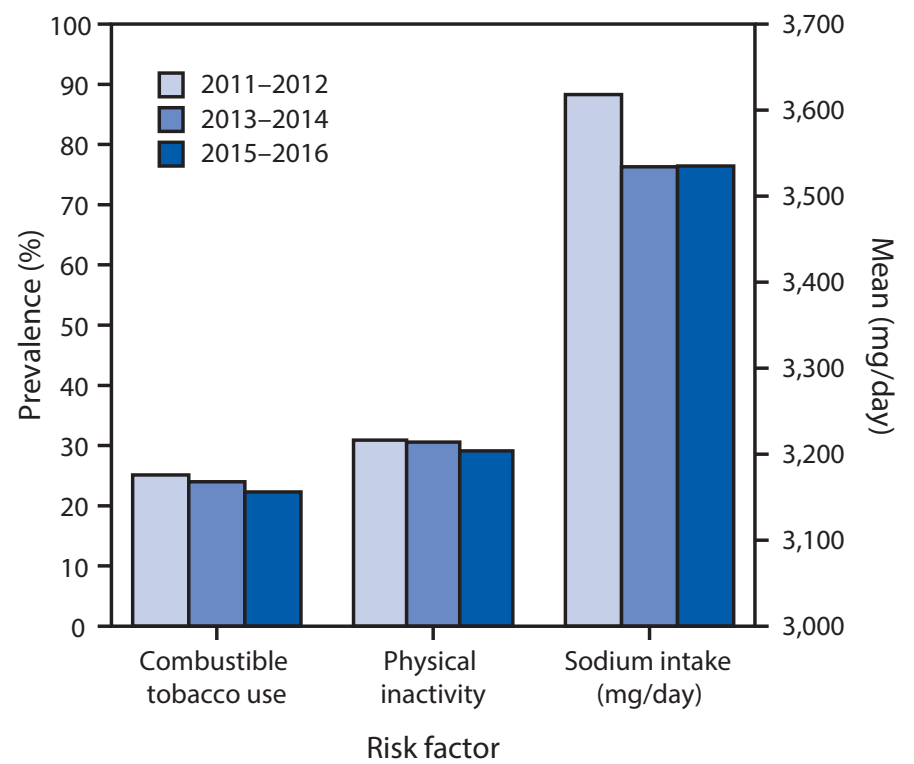

Source: National Survey on Drug Use and Health; Substance Abuse and Mental Health Services Administration; National Health and Nutrition Examination Survey; National Center for Health Statistics; CDC; National Health Interview Survey (NHIS). * Combustible tobacco use was defined as current use of combustible tobacco products (cigarettes, cigars, or pipe) among adults (aged $\geq 18$ years) with complete data to determine tobacco use.

† The 2008 Physical Activity Guidelines for Americans (http://www.health.gov/ PAGuidelines/) recommend that all adults should avoid inactivity and that some physical activity is better that none. NHIS questions ask about frequency of participation in light to moderate-intensity and vigorous-intensity leisuretime physical activities for at least 10 minutes. Questions are phrased in terms of current behavior and lack a specific reference period. Physical inactivity is defined as reporting no light to moderate or vigorous leisure-time physical activity for at least 10 minutes.

$\S$ Sodium intake ( $\mathrm{mg} /$ day) was estimated among adults aged $\geq 18$ years with a complete and reliable first day 24 -hour dietary recall (collected in-person at the mobile examination center).

" For combustible tobacco use and physical inactivity, t-test $p$-values $<0.01$ comparing 2015-2016 with 2011-2012, adjusted for sex, age group, and race/ethnicity.

has been shown to have a substantial effect on preventing acute cardiovascular events $(11,12)$.

The data in this report serve as a baseline for Million Hearts 2022. These findings suggest that in addition to universal strategies aimed at the entire population with and at risk for CVD, there is a need to focus action on high-burden, high-risk subsets of the population. For example, opportunities for risk factor prevention and management among younger adults are of particular importance given the increase in heart disease mortality observed from 2010 to 2015 among adults aged 35-64 years in approximately half of U.S. counties (3). Compared with adults aged $\geq 65$ years, younger adults were less likely to be using aspirin or taking a statin when indicated and were more likely to use combustible tobacco and have an elevated daily sodium intake. Furthermore, only approximately half of adults aged 35-64 years 
with hypertension have their BP under control. If the population deficits for each risk factor in this analysis (e.g., 9.0 million persons who are not taking aspirin as recommend) are summed, they represent approximately 213 million opportunities for better risk factor prevention and management, many of which might be present in the same person. More than half of these opportunities are among adults aged 35-64 years.

Additional demographic disparities in risk factor prevalence present opportunities to develop and implement culturally and linguistically tailored and effective interventions. For example, compared with whites, Hispanics were less likely to use aspirin for secondary prevention or take a statin when indicated, blacks were less likely to have their blood pressure under control, and persons of "other" racial/ethnic groups, including American Indians and Alaska Natives, were more likely to use combustible tobacco products. Other studies confirm the existence of these disparities (13-15).

Included in the Million Hearts 2022-recommended clinical strategies are self-measured blood pressure monitoring with clinical support, ${ }^{* * * *}$ standardized treatment protocols, ${ }^{, \dagger \dagger \dagger}$ reduced out-of-pocket costs $\$ \mathbb{S} \mathbb{S}$ and adherence approaches $\mathbf{S 9 9}$ for medications, clinician-driven tobacco assessment and treatment, ${ }^{* * * * *}$ increasing awareness of the effect of particle pollution (including tobacco smoke, automobile or diesel exhaust, and wood smoke $)^{\dagger \dagger \dagger \dagger \dagger}$ on persons with known heart disease, and using clinical data to identify persons with undiagnosed conditions. $\$ \$ \$ \$ S$ Community-based strategies include comprehensive smoke-free policies, $\mathbf{9 9 9 9 9}$ evidence-based tobacco cessation campaigns, ${ }^{* * * * * *}$ sodium reduction strategies, ${ }^{\dagger \dagger \dagger \dagger \dagger \dagger}$ built environment approaches ${ }^{\$ \Phi \$ \$ \$ \$}$ to increase physical activity, increased access to places for physical activity, 999999 and peer support programs. ${ }^{* * * * * * *}$ Public and private partners, such as the Agency for Healthcare Research and Quality's

**** https://millionhearts.hhs.gov/tools-protocols/smbp.html.

t†t† https://millionhearts.hhs.gov/tools-protocols/protocols.html.

\$SS\$ https://www.thecommunityguide.org/findings/cardiovascular-diseasereducing-out-pocket-costs-cardiovascular-disease-preventive-services; https:// www.thecommunityguide.org/findings/tobacco-use-and-secondhandsmoke-exposure-reducing-out-pocket-costs-evidence-based-cessation.

9999 https://millionhearts.hhs.gov/tools-protocols/medication-adherence.html.

***** https://millionhearts.hhs.gov/files/Tobacco-Cessation-Action-Guide.pdf.

$\dagger+\dagger_{\dagger}$ https://millionhearts.hhs.gov/tools-protocols/tools/particle-pollution.html.

\$SSSS https://millionhearts.hhs.gov/tools-protocols/hiding-plain-sight/index.html.

9999 https: / / www.thecommunityguide.org/findings/ tobacco-use-and-secondhand-smoke-exposure-smoke-free-policies.

****** https://www.thecommunityguide.org/findings/tobacco-use-andsecondhand-smoke-exposure-mass-reach-health-communicationinterventions; https://www.cdc.gov/tobacco/campaign/tips/index.html

计柿 https://www.cdc.gov/vitalsigns/sodium.

$\$ S \$ S S S$ t t p s: / / ww w.thecommunityguide.org/findings/ physical-activity-built-environment-approaches.

999999 h t t p : / / www.thecommunityguide.org/findings / physical-activity-creating-or-improving-places-physical-activity.

******* h t t ps: / / www.the communityguide.org/findings / physical-activity-social-support-interventions-community-settings.

\section{Summary}

What is already known about this topic?

The decline in cardiovascular disease (CVD) mortality rate has begun to plateau in the general population and has increased among some subpopulations; the prevalence of CVD risk factors remains high. Million Hearts 2022 was launched to focus the nation on high-impact, evidence-based strategies to prevent one million acute cardiovascular events over five years.

What is added by this report?

During 2015-2016, adult sodium intake averaged 3,535 mg/day and the prevalences of blood pressure control, combustible tobacco use, and physical inactivity were $48.5 \%, 22.3 \%$ and $29.1 \%$, respectively. Compared with 2011-2012, significant improvements were observed in combustible tobacco use and physical inactivity, but the prevalence of aspirin use to prevent CVD declined.

What are the implications for public health practice?

A concerted effort to implement evidence-based strategies is needed to achieve the Million Hearts 2022 goal.

EvidenceNOW initiative, ${ }^{\dagger \dagger}{ }^{\dagger \dagger}+\dagger^{\dagger}$ state and local departments of health, the National Association of Community Health Centers, and Target:BP\$S\$S\$ from the American Heart Association and the American Medical Association, are actively implementing these strategies.

The findings in this report are subject to at least five limitations. First, some data used in this analysis are self-reported and subject to recall and social desirability biases. Second, when the data assessing aspirin use for primary CVD prevention were collected, multiple clinical guidelines existed; definitions from the current U.S. Preventive Services Task Force recommendation, published in 2016, were retrospectively applied for this analysis. Third, the American College of Cardiology and American Heart Association's (ACC/ AHA) cholesterol management guideline, released in November 2013 with a focus on high-intensity statin use (treatment that lowers low-density lipoprotein cholesterol by approximately $\geq 50 \%$ ) among eligible persons at high risk for cardiovascular events, was retrospectively applied to the 2011-2012 data. NHANES data allow for reporting only on general statin use and not statin intensity, which might result in overestimating the prevalence of the statineligible population meeting recommendations. Fourth, Million Hearts focuses on the "ABCS," which include smoking cessation through assessment and treatment in a clinical setting. However, population-level data for this indicator do not exist so only combustible tobacco use prevalence can be monitored, but not clinical actions that support cessation. Finally, as with many national data collection efforts, there is a 2-3 year data lag for some indicators. As a result, incongruous data cycles are reported in this analysis.

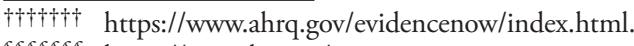

\$s\$s\$s\$ https://targetbp.org/. 
Morbidity and Mortality Weekly Report

TABLE 2. Current prevalence of Million Hearts 2022 community risk factors for cardiovascular disease among adults — United States, $2015-2016$

\begin{tabular}{|c|c|c|c|c|}
\hline Risk factor/Demographic group & $\%$ (SE) & $(95 \% \mathrm{Cl})$ & No. (millions)* & t-test $p$-value ${ }^{\dagger}$ \\
\hline \multicolumn{5}{|c|}{ Combustible tobacco use among adults aged $\geq 18$ years $^{\S}-$ NSDUH, 2015-2016 } \\
\hline Total & $22.3(0.2)$ & $(21.9-22.7)$ & 54.1 & - \\
\hline $\begin{array}{l}\text { Sex } \\
\text { Male } \\
\text { Female }\end{array}$ & $\begin{array}{l}26.7(0.3) \\
18.1(0.2)\end{array}$ & $\begin{array}{l}(26.1-27.3) \\
(17.6-18.6)\end{array}$ & $\begin{array}{l}31.3 \\
22.8\end{array}$ & $\begin{array}{r}\text { reference } \\
<0.001\end{array}$ \\
\hline $\begin{array}{l}\text { Age group } \text { (yrs) } \\
18-24 \\
25-44 \\
18-44 \\
45-64 \\
65-74 \\
\geq 65 \\
\geq 75\end{array}$ & $\begin{array}{r}24.4(0.4) \\
27.4(0.3) \\
26.6(0.2) \\
23.0(0.4) \\
13.5(0.6) \\
10.4(0.4) \\
5.3(0.5)\end{array}$ & $\begin{array}{r}(23.7-25.1) \\
(26.8-28.0) \\
(26.1-27.1) \\
(22.2-23.7) \\
(12.4-14.6) \\
(9.5-11.3) \\
(4.4-6.2)\end{array}$ & $\begin{array}{r}7.5 \\
22.7 \\
30.2 \\
19.1 \\
3.7 \\
4.8 \\
1.0\end{array}$ & $\begin{array}{r}<0.001 \\
<0.001 \\
<0.001 \\
\text { reference } \\
<0.001 \\
<0.001 \\
<0.001\end{array}$ \\
\hline $\begin{array}{l}\text { Race/Ethnicity } \\
\text { White, non-Hispanic } \\
\text { Black, non-Hispanic } \\
\text { Asian, non-Hispanic } \\
\text { Hispanic } \\
\text { Other }\end{array}$ & $\begin{array}{l}24.0(0.3) \\
24.7(0.6) \\
10.3(0.8) \\
16.0(0.4) \\
30.8(1.0)\end{array}$ & $\begin{array}{r}(23.4-24.6) \\
(23.6-25.8) \\
(8.9-11.9) \\
(15.2-16.7) \\
(28.9-32.8)\end{array}$ & $\begin{array}{r}37.7 \\
7.0 \\
1.4 \\
6.0 \\
1.9\end{array}$ & $\begin{array}{r}\text { reference } \\
0.349 \\
<0.001 \\
<0.001 \\
<0.001\end{array}$ \\
\hline
\end{tabular}

See table footnotes on next page.

Heart disease and stroke are leading causes of death in the United States; their risk factors are prevalent in the general population and are particularly high among certain subgroups. Evidence-based strategies for preventing acute cardiovascular events exist, with 213 million opportunities for better risk factor prevention and management. It will require a concerted national implementation effort to prevent one million acute cardiovascular events by 2022 .

\section{Acknowledgments}

Chandler McClellan, Substance Abuse and Mental Health Services Administration; Janet S. Wright, CDC.

Corresponding author: Hilary K. Wall, hwall@cdc.gov, 770-488-8172.

\footnotetext{
${ }^{1}$ Division for Heart Disease and Stroke Prevention, CDC; ${ }^{2}$ Division of Nutrition, Physical Activity, and Obesity, CDC; ${ }^{3}$ Office on Smoking and Health, CDC.

All authors have completed and submitted the ICMJE form for disclosure of potential conflicts of interest. No potential conflicts of interest were disclosed.
}

\section{References}

1. Mensah GA, Wei GS, Sorlie PD, et al. Decline in cardiovascular mortality: possible causes and implications. Circ Res 2017;120:366-80. https://doi.org/10.1161/CIRCRESAHA.116.309115

2. Yang Q, Tong X, Schieb L, et al. Vital Signs: Recent trends in stroke death rates-United States, 2000-2015. MMWR Morb Mortal Wkly Rep 2017;66:933-9. https://doi.org/10.15585/mmwr.mm6635e1

3. Vaughan AS, Ritchey MD, Hannan J, Kramer MR, Casper M. Widespread recent increases in county-level heart disease mortality across age groups. Ann Epidemiol 2017;27:796-800. https://doi.org/10.1016/j. annepidem.2017.10.012

4. Benjamin EJ, Virani SS, Callaway CW, et al.; American Heart Association Council on Epidemiology and Prevention Statistics Committee and Stroke Statistics Subcommittee. Heart disease and stroke statistics-2018 update: a report from the American Heart Association. Circulation 2018;137:e67-492. https://doi.org/10.1161/CIR.0000000000000558
5. Frieden TR, Wright JS, Conway PH. Is rapid health improvement possible? Lessons from the Million Hearts Initiative. Circulation 2017;135:1677-80. https://doi.org/10.1161/CIRCULATIONAHA.117.027461

6. Ritchey MD, Loustalot F, Wall HK, et al. Million Hearts: description of the national surveillance and modeling methodology used to monitor the number of cardiovascular events prevented during 2012-2016. J Am Heart Assoc 2017;6:e006021. https://doi.org/10.1161/JAHA.117.006021

7. Wright JS. Million Hearts 2022: focusing action for impact. Presented at CDC Public Health Grand Rounds, Atlanta, GA; February 20, 2018. https:// www.cdc.gov/grand-rounds/pp/2018/20180220-million-hearts-2022.html

8. CDC. National Health and Nutrition Examination Survey Data. Hyattsville, MD: US Department of Health and Human Services, CDC; 2018. https://www.cdc.gov/nchs/nhanes/index.htm

9. SAMHSA. National Survey on Drug Use and Health Data. Rockville, MD: US Department of Health and Human Services, SAMHSA; 2018. https://www. samhsa.gov/data/data-we-collect/nsduh-national-survey-drug-use-and-health

10. CDC. National Health Interview Survey Data. Hyattsville, MD: US Department of Health and Human Services, CDC; 2018. https://www. cdc.gov/nchs/nhis/index.htm

11. Danaei G, Ding EL, Mozaffarian D, et al. The preventable causes of death in the United States: comparative risk assessment of dietary, lifestyle, and metabolic risk factors. PLoS Med 2009;6:e1000058. https://doi. org/10.1371/journal.pmed. 1000058

12. Farley TA, Dalal MA, Mostashari F, Frieden TR. Deaths preventable in the U.S. by improvements in use of clinical preventive services. Am J Prev Med 2010;38:600-9. https://doi.org/10.1016/j.amepre.2010.02.016

13. Whelton PK, Einhorn PT, Muntner P, et al.; National Heart, Lung, and Blood Institute Working Group on Research Needs to Improve Hypertension Treatment and Control in African Americans. Research needs to improve hypertension treatment and control in African Americans. Hypertension 2016;68:1066-72. https://doi.org/10.1161/ HYPERTENSIONAHA.116.07905

14. Qato DM, Lee TA, Durazo-Arvizu R, et al. Statin and aspirin use among Hispanic and Latino adults at high cardiovascular risk: findings from the Hispanic Community Health Study/Study of Latinos. J Am Heart Assoc 2016;5:e002905. https://doi.org/10.1161/JAHA.115.002905

15. Odani S, Armour BS, Graffunder CM, Garrett BE, Agaku IT. Prevalence and disparities in tobacco product use among American Indians/Alaska Natives-United States, 2010-2015. MMWR Morb Mortal Wkly Rep 2017;66:1374-8. https://doi.org/10.15585/mmwr.mm6650a2 
Morbidity and Mortality Weekly Report

TABLE 2. (Continued) Current prevalence of Million Hearts 2022 community risk factors for cardiovascular disease among adults — United States, 2015-2016

\begin{tabular}{|c|c|c|c|c|}
\hline Risk factor/Demographic group & $\%(\mathrm{SE})$ & $(95 \% \mathrm{Cl})$ & No. (millions)* & t-test $p$-value ${ }^{\dagger}$ \\
\hline \multicolumn{5}{|c|}{ Physical inactivity among adults aged $\geq 18$ years" - NHIS, 2015-2016 } \\
\hline Total & $29.1(0.4)$ & $(28.3-29.8)$ & 70.7 & - \\
\hline $\begin{array}{l}\text { Sex } \\
\text { Male } \\
\text { Female }\end{array}$ & $\begin{array}{l}27.3(0.4) \\
30.7(0.5)\end{array}$ & $\begin{array}{l}(26.4-28.2) \\
(29.9-31.6)\end{array}$ & $\begin{array}{l}31.9 \\
38.7\end{array}$ & $\begin{array}{r}\text { reference } \\
<0.001\end{array}$ \\
\hline \multicolumn{5}{|l|}{ Age group" (yrs) } \\
\hline $18-24$ & $22.5(0.9)$ & $(20.9-24.3)$ & 6.9 & $<0.001$ \\
\hline $25-44$ & $23.6(0.5)$ & $(22.6-24.5)$ & 19.5 & $<0.001$ \\
\hline $18-44$ & $23.3(0.5)$ & $(22.4-24.2)$ & 26.4 & $<0.001$ \\
\hline $45-64$ & $30.1(0.5)$ & $(29.0-31.2)$ & 25.0 & reference \\
\hline $65-74$ & $34.2(0.7)$ & $(32.9-35.6)$ & 9.3 & $<0.001$ \\
\hline$\geq 65$ & $41.2(0.6)$ & $(40.0-42.3)$ & 19.1 & $<0.001$ \\
\hline$\geq 75$ & $51.2(0.8)$ & $(49.5-52.8)$ & 9.8 & $<0.001$ \\
\hline \multicolumn{5}{|l|}{ Race/Ethnicity } \\
\hline White, non-Hispanic & $26.4(0.4)$ & $(25.6-27.3)$ & 41.5 & reference \\
\hline Black, non-Hispanic & $36.9(0.8)$ & $(35.3-38.6)$ & 10.5 & $<0.001$ \\
\hline Asian, non-Hispanic & $24.6(1.4)$ & $(22.0-27.5)$ & 3.3 & 0.916 \\
\hline Hispanic & $36.1(0.9)$ & $(34.3-38.0)$ & 13.6 & $<0.001$ \\
\hline Other & $24.5(1.3)$ & $(22.1-27.0)$ & 1.5 & 0.828 \\
\hline Risk factor/Demographic group & Mean (SE) & $(95 \% \mathrm{Cl})$ & No. (millions)* & $p$-value ${ }^{\dagger}$ \\
\hline \multicolumn{5}{|c|}{ Average dietary sodium intake (mg/day) among adults aged $\geq 18$ years ${ }^{* *}-$ NHANES, 2015-2016 } \\
\hline Total & $3,535(41)$ & $(3,452-3,618)$ & $\mathrm{N} / \mathrm{A}$ & - \\
\hline \multicolumn{5}{|l|}{ Sex } \\
\hline Male & $4,095(65)$ & $(3,964-4,226)$ & $\mathrm{N} / \mathrm{A}$ & reference \\
\hline Female & $3,013(38)$ & $(2,936-3,089)$ & N/A & $<0.001$ \\
\hline \multicolumn{5}{|l|}{ Age group" (yrs) } \\
\hline $18-24$ & $3,733(109)$ & $(3,515-3,951)$ & $\mathrm{N} / \mathrm{A}$ & 0.1205 \\
\hline $25-44$ & $3,834(75)$ & $(3,683-3,985)$ & $\mathrm{N} / \mathrm{A}$ & $<0.001$ \\
\hline $18-44$ & $3,809(68)$ & $(3,673-3,946)$ & $\mathrm{N} / \mathrm{A}$ & $<0.001$ \\
\hline $45-64$ & $3,524(50)$ & $(3,424-3,625)$ & $\mathrm{N} / \mathrm{A}$ & reference \\
\hline $65-74$ & $3,092(96)$ & $(2,899-3,284)$ & N/A & $<0.001$ \\
\hline$\geq 65$ & $2,947(66)$ & $(2,815-3,078)$ & $\mathrm{N} / \mathrm{A}$ & $<0.001$ \\
\hline$\geq 75$ & $2,733(92)$ & $(2,549-2,918)$ & $\mathrm{N} / \mathrm{A}$ & $<0.001$ \\
\hline \multicolumn{5}{|l|}{ Race/Ethnicity } \\
\hline White, non-Hispanic & $3,515(54)$ & $(3,406-3,624)$ & $\mathrm{N} / \mathrm{A}$ & reference \\
\hline Black, non-Hispanic & $3,364(60)$ & $(3,243-3,484)$ & $\mathrm{N} / \mathrm{A}$ & 0.0047 \\
\hline Asian, non-Hispanic & $3,831(114)$ & $(3,601-4,062)$ & $\mathrm{N} / \mathrm{A}$ & 0.0632 \\
\hline Hispanic & $3,582(65)$ & $(3,450-3,713)$ & $\mathrm{N} / \mathrm{A}$ & 0.3540 \\
\hline Other & $3,726(283)$ & $(3,156-4,296)$ & $\mathrm{N} / \mathrm{A}$ & 0.6184 \\
\hline
\end{tabular}

Sources: NSDUH; Substance Abuse and Mental Health Services Administration; NHANES; National Center for Health Statistics; CDC National Health Interview Survey (NHIS); NCHS; CDC.

Abbreviations: $\mathrm{Cl}=$ confidence interval; $\mathrm{N} / \mathrm{A}=$ not applicable; NHANES = National Health and Nutrition Examination Survey; NSDUH = National Survey on Drug Use and Health; SE = standard error.

* Population counts are calculated using the American Community Survey 2013 or 2015 annual Public Use Microdata Sample files, the latest available file after data collection in the 2013-2014 and 2015-2016 survey cycles, respectively. https://wwwn.cdc.gov/nchs/nhanes/ResponseRates.aspx.

$\dagger$ P-values adjusted for sex, age group, and race/ethnicity using logistic regression.

$\S$ Includes current use of combustible tobacco products (cigarettes, cigars, or pipes) among adults ( $\geq 18$ years). Current cigarette smoking defined as an answer of "yes" to the question "Have you smoked at least 100 cigarettes in your entire life?" and an answer of "Within the past 30 days" to the question "How long has it been since you last smoked part or all of a cigarette?" Current cigar smoking defined as an answer of "Within the past 30 days" to the question "How long has it been since you last smoked part or all of any type of cigar?" Current pipe smoking defined as an answer of "yes" to the question "During the past 30 days, have you smoked tobacco in a pipe, even once?"

I The 2008 Physical Activity Guidelines for Americans (https://www.health.gov/PAGuidelines/) recommend that all adults should avoid inactivity and that some physical activity is better that none. NHIS questions ask about frequency of participation in light to moderate-intensity and vigorous-intensity leisure-time physical activities for at least 10 minutes. Questions are phrased in terms of current behavior and lack a specific reference period. Physical inactivity is defined as reporting no light to moderate or vigorous leisure-time physical activity for at least 10 minutes.

** Includes adults (aged $\geq 18$ years) with a complete and reliable 1st day 24-hour dietary recall (collected in-person at the mobile examination center). Sodium values are not adjusted for salt added during food preparation or at the table. 